\title{
Engineering project based cooperative training model for professional graduates
}

\author{
OU Shifeng, CHEN Chen, HAN Ruirui, GAO Ying \\ School of Science and Technology for Opto-electronic Information \\ Yantai University \\ Yantai 264005, China \\ claragaoying@126.com
}

\begin{abstract}
In 21st century, the cooperative training and innovative talent have become the key points for the higher education. However, the lack of innovative capacity is still a big issue in professional graduate education for our country. In view of this problem, a new cooperative training model for professional graduates based on engineering project is proposed in this paper. In this model, the cultivation of professional graduates focus on improving the practical ability and innovation ability of postgraduates by taking the engineering project as a link.
\end{abstract}

Keywords—Engineering project; professional graduate; Cooperative training model.

\section{INTRODUCTION}

Since the implementation of the academic degree system in China for more than 30 years, the scale of enrollment has been expanded, the enrollment system as well as the education system has been improved continuously. It has basically formed a set of postgraduate education system which conforms to our basic national conditions, the graduate education in our country has cultivated a large number of high-level technical personnel and talented managers. However, with the international development of the economy and the emerging science and technology, the demand of the state and society is becoming more and more diversified, and the classification and stratification are contradictory to the single education model for the graduate students. Graduate education is no longer limited to the college tutor's "spoon-fed" theory guidance, the economic development is relying on the theoretical basis of excellent talent, but the international economic development and the rapid development of science and technology needs a lot of engineering experience and independent practical ability, teamwork ability of high-quality talent. However, there are no differences in the training mode for the graduate student in academic and professional degree [1].

In order to meet the needs of the state and society for the practical talents, our country has begun to promote the professional education system, and continue to explore more suitable training new models for China's professional graduate students, such as the implementation of colleges and enterprises, "two mentors" business model, the new training model to a certain extent, more adapt to the development of professional graduate students, but there are still "two tutors" training effect which is not ideal, schoolenterprise cooperation to develop fault phenomenon. The collaborative mode of school and enterprise is the essential requirement of the development of postgraduate education in professional degree, which is in line with the law of education cultivated by graduate students and is conducive to the connection between the cultivation of graduate students' ability and social needs [3]. It is a profound relationship with the profound meaning of higher education system reform [2]. In order to further to solve the problem of the synergy between colleges to cultivate the specialized degree graduate student, must first clear training objective is to cultivate composite social needs practice talents, so it is necessary to be guided by the project [4]. It is urgent to accelerate the reform of the training system and model of the applied type personnel training system, which are the carrier of the project and the training mode of the school enterprise. Through the integration of resources in both colleges and universities, the formation of engineering projects as a link, the theory of university guidance and practice of business practice in parallel with the professional degree graduate school students to cultivate a new model [5].

The cultivation of the professional degree graduate should improve the graduate student's practical ability and innovative ability as the center, the project as a link, the synergy between colleges cultivate ideas throughout the graduate student education, all the positive factors: build collaborative culture of a new platform, create favorable atmosphere of synergy between colleges to cultivate, in order to achieve the purpose of improving the quality of professional degree graduate education in an all-round way. The cultivation of professional degree graduate students should focus on improving the practical ability and innovation ability of postgraduates, taking the project as a link, and cooperating with the school and enterprise to cultivate the whole process of postgraduate education, and actively build a new platform for the co-cultivation of school and enterprise. To the project as the carrier of the professional degree graduate school-enterprise collaborative training model, including; projects, universities, enterprises and talent four parts. The collaborative mode of the school - enterprise collaborative training is the integration and optimization of the four parts of the project, the university, the enterprise and the talent, and forms a kind of integration of various resources improved university-enterprise cooperation pattern of graduate student training. 


\section{Comparison of Three Training Modes of Professional Degree Postgraduates}

Training objectives: Joint training, and entrusted to project as a carrier of professional degree graduate cooperative education mode between colleges goal is developed to solve practical problems, the high quality professional talents.

Training mode: joint training is a joint training of colleges and universities, the implementation of "double tutor" system, the enterprise builds internship platform for graduate students to practice; the graduate student is basically detached from the university, independent in enterprise learns and practice; to the project as a carrier of professional degree graduate student synergy between colleges and enterprise training mode is the common set of professional degree graduate student to complete the project, university teacher guiding theory, enterprise mentor to guide practice, accumulated in the graduate students in the process of project experience, truly see practical results, through project completion test the graduate student's practice.

Degree standard: The topic of research is based on the practical problems and the content of the work to be solved in the course of the practice of the enterprise. The thesis takes the project as the carrier school and enterprise collaborative training graduate thesis from the university and enterprises jointly developed the project, the project encountered problems, the project process, the completion of the situation and conclusions. According to the professional degree graduate students in the three training mode is relatively easy to see, professional graduate students as a graduate student, the goal is to cultivate high quality application and creative talents. The three training models all focus on the cultivation of practical ability and professional ability of professional degree graduate students. But the process of joint training will continue to lack of communication between colleges and universities and the "double tutor" training ineffective phenomenon. The graduate students can not fully apply the theoretical knowledge to in practice, the practical effect of the evaluation mechanism is not effective, the practice set up by the enterprise is useless, and the training program is in the form of form. And the entrusted training makes the theoretical part of the practical problems encountered by the graduate students in the enterprise due to unguided guidance, the lack of professional basic knowledge, the same lack of effective practice evaluation mechanism. Project-based professional degree graduate school-enterprise collaborative training model to a certain extent, to avoid the drawbacks of the other two training modes, to strengthen the exchange of colleges and enterprises, to achieve the exchange of colleges and enterprises to lay the foundation for further refinement of the professional. The evaluation mechanism of the graduate students' training process is based on the actual project, which embodies the training objectives of cultivating the professional and applied talents to meet the social needs [3].

\section{NEW Model BASED ON ENGINEERING PROJECT}

\section{A. Improving the school-enterprise collaborative training model platform}

In the university to join the enterprise project case teaching process: professional degree graduate training, should be closely integrated with the actual enterprise project establishment, design, tentative, test and other processes. Only in the professional degree graduate courses to join the enterprise project examples of teaching, graduate students can learn the basic theoretical knowledge combined with and practice projects, to achieve the mastery, learn by analogy, will have a deeper understanding and more intuitive understanding of theoretical knowledge.

Coordinate the joint goals of graduate school and enterprise cooperative training mode for professional degree graduates: enterprises in order to meet their own production and technical needs, the university as a training to a high level of professional quality of the talent output base, these talents can be applied to the production of technology for enterprises to create high efficiency, high production efficiency. However, under the influence of the traditional academic graduate education, the university has paid more attention to the cultivation of postgraduates in theory and academia, and neglected the cultivation of the practice and application ability of postgraduates in professional colleges. Enterprise training objectives can not be harmonized. Therefore, it is very important to harmonize the common goal of graduate professional school-enterprise collaborative training model.

\section{B. Selecting appropriate project}

As the carrier of professional degree graduate students and school enterprise collaborative training mode, engineering project plays a supporting role in the whole training mode. Therefore, the selection of engineering projects is of vital importance to the quality of education and educational results of collaborative training model. However, for the cultivation of graduate students in most colleges and universities, college tutors still dominate the research direction and engineering projects of postgraduates, and the research projects studied by graduate students come from one direction of the tutor's project. However, many of the professional graduate students of the mentor of the subject is not a practical project, but a theoretical project, resulting in a large number of professional graduate degree of study time for the formula and theoretical research, and then write papers, rather than in the project Research on Practical Problems of Practical Learning. Therefore, college instructors selected for their own projects with graduate students should be combined with the needs of the enterprise, and the enterprise supervisor jointly elected in accordance with the engineering project training objectives of graduate students, to the project as a guide, for graduate students in the completion of the project in theory and practice, the full exercise of the ability to solve practical problems true, school enterprise collaborative training benefit scheme, and achieve the school, enterprise and graduate three win-win situation. 


\section{Relying on the pole of project link}

The project is not only the key to the cultivation of graduate students, but also the link between college instructor and enterprise mentor. There is no project to do the carrier of the school-based training mode under the "two mentors" training ineffective, a large part of the reason is that there is no common carrier between the two tutors. Double tutors to complete their respective guidance tasks, each belonging to different units, did not reach the double tutor training scheme combines the advantages of the original design, it will be unable to complete the common professional degree graduate training high level occupation type and application type talents. In addition, we should strengthen the continuous training of professional graduate students in the project, double tutors on the whole project follow-up, including the research, project, project progress, project completion, and the graduate of the project are summarized in the final stage, really let the graduate students gain practical experience in the project, understand the project process, for the future to enter social post occupation based solid play. The tutors also can exchange experience and learn from each other in the course of the follow-up instruction, and accumulate the experience for the future graduate education of professional degree.

\section{Improveing the effectiveness of evaluation system}

The evaluation system of practical effect of engineering project is an important means to guarantee the cooperative mode of graduate school enterprise cooperation. Through the evaluation system, we can find the problems in the training mode, and provide the basis for actively improving and adjusting the training methods to obtain the effective postgraduate education. The evaluation system of the practical effect of the project is to collect the relevant information according to the expected effect of the training, set the relevant evaluation index and collect the graduate students to complete the index in the course of the training. The data are quantitatively and qualitatively analyzed by the mathematical method, Graduate students do the work of the various stages of the project to make a comprehensive, accurate and objective evaluation. Scientific evaluation can promote the effective operation of the cooperative mode of graduate school and enterprise, but also can fully mobilize the enthusiasm of school enterprises and professional degree graduate students to participate in the project, finally, the three party interests can be equally distributed.

The practical effect evaluation system of project should be established in three aspects: cultivating thought, evaluation subject and evaluation content of professional degree graduate student. First of all, in the ideological training of graduate students, because the different regions of colleges and universities can control the different effective resources, different professional graduate students have different training needs, evaluation mechanism can not be one size fits all, but should effectively use the existing disciplines, local enterprise resources and talent base, integrate of multiple interests, to improve the quality of training, service needs evaluation system. Secondly, in the evaluation of the main body, for colleges and universities, graduate students and enterprises three different themes to establish different evaluation criterion, the establishment of three self-evaluation and mutual evaluation criteria. Finally, in the content of evaluation, should not only to pay attention to the short-term evaluation standard , but also to focus on the establishment and improvement of long-term evaluation system, not only to the cooperative training mode of effect evaluation of the professional, but also on the related professional evaluation, disciplines to evaluate, and then the college as a whole professional graduate students to evaluate the effect of training, in order to achieve long-term sustainable development of graduate students to achieve the purpose of sustainable development.

\section{SUMMARY}

With the "service demand, improve quality" as the main line, optimize the structure, improve quality, and comprehensively enhance the level of graduate education and graduate education is the current development of China's graduate education and the ultimate goal. This paper compares the two models of school enterprise collaborative training with specialized graduate students with engineering project as the carrier and joint training and entrusted training, the results showed that with the project as the carrier of professional degree training mode of school enterprise cooperation to graduate professional degree in the direction of reform, is a landmark exploration in the process of graduate education reform. But this new mode of cultivation is still in the process of exploration, it needs continuous improvement according to the purpose of training. In this paper, the establishment of a new training model put forward specific views: to build a platform, selected projects, strengthen exchanges, improve performance and so on. In addition, in the course of the development of graduate education is also inseparable from the colleges and universities, the exchange of each region, learn from each other, the colleges and universities need to combine their own practical problems continue to optimize the professional postgraduate training mechanism.

\section{ACKNOWLEDGMENT}

This research was supported by the Graduate Education Innovation Project of Shandong Province (SDYY15123). 


\section{REFERENCES}

[1] Z. H. Huang, Full-time education master training model based on the coordinated innovation. CN: Southwest University, 2014.

[2] D. H. Wang, School-enterprise cooperation to cultivate the master's degree collaborative development mechanism. CN:Chongqing University, 2008.

[3] J. L. Li, Research on joint training mechanism reform of graduate students under collaborative innovation environment. CN: University of Science \& Technology China, 2015.

[4] Information on http://www.chinadegrees.cn/

[5] Information on http://xwb.sdedu.gov.cn/sdadgei/index.php 